\title{
Zabo Farming System- A Sustainable Farming based on Traditional Knowledge for Natural Resource Management Practiced by Tribal in Nagaland, India
}

\author{
Nchumthung Murry ${ }^{1 *}$ and Sanjoy Das ${ }^{2}$ \\ ${ }^{1}$ Department of Agricultural Economics, Nagaland University, SASRD, Medziphema, India \\ ${ }^{2}$ Department of Agricultural Economics, Nagaland University, SASRD, Medziphema, India \\ "Corresponding author: nch.murry@gmail.com (ORCID ID: 0000-0001-9850-0051)
}

Paper No. 900

Received: 21-03-2021

Revised: 26-05-2021

\begin{abstract}
Various models of sustainable indigenous farming practices exist among the tribal population, especially among tribes of the North East Region of India. These practices are often considered as an alternative to old age practices of shifting cultivation which has a negative impact on the natural ecosystem in many ways. This paper focuses on the practices and importance of the Zabo farming system, an indigenous farming model practiced by the Naga tribe in Nagaland. The word "Zabo" means impounding of water in the local dialect. Zabo farming comprises integrated agricultural activities such as forest land for silviculture, water harvesting, animal husbandry, and paddy cultivation along the slope of the hills.
\end{abstract}

\section{HIGHLIGHTS}

- Zabo a Sustainable Indigenous Farming Model practiced in the state of Nagaland.

0 Farming approach based on farming integration and conservation natural resources.

Keywords: Nagaland, indigenous, sustainable, tribal, Zabo

Nagaland became the $16^{\text {th }}$ state of an Indian union located in the northeastern region of India. More than half of the state population lives in rural areas, and agriculture is the main occupation for more than $70 \%$ of the population. Shifting / Jhum cultivation which is an old traditional system of farming, is widely practiced in the state. It is believed that the old age practiced of shifting cultivation dates back to as old as the Neolithic period around 7000 BC (Borthakur 1982). Exploitation nature of shifting cultivation on the natural ecosystem, biodiversity, and cause of deforestation it is not considered as a sustainable approach for farming and land management practice. Over the years tribal farmer through their ingenious skill and experiences has developed a various alternative farming system of shifting cultivation such as alder based farming system, zabo farming system and wet terrace rice cultivation, etc. The present paper attempts to elaborate on the evolution and management practices of zabo farming system practiced by tribal farmers of in the state of Nagaland.

\section{Scope of Indigenous Farming Practices}

A different system of sustainable indigenous farming practices and indigenous knowledge exists among the tribal people in North East Region. In Nagaland, indigenous farming systems viz., alder based farming system, zabo farming, and wet terrace rice cultivation etc. are practices which widely. These farming practices are evolved by locals through

How to cite this article: Murry, N. and Das, S. 2021. Zabo Farming System- A Sustainable Farming based on Traditional Knowledge for Natural Resource Management Practiced by Tribal in Nagaland, India. IJAEB, 14(2): 203-205.

Source of Support: None; Conflict of Interest: None 
their farming experience and skills and had been in practice since olden times. There is a need for extensive research and extension mechanism to be explored and potentially improved for sustainable livelihood management in the hill region of India. Apart from addressing the old age faulty practices of shifting cultivation, the adoption of Indigenous knowledge and indigenous farming practices will serve as a cornerstone in the conversion of hill farming into a model organic farming hub. The region which is considered as 'organic by default' can be strategically converted to 'organic by design' in many hilly regions of North East India.

\section{Zabo Farming System}

The term Zabo literally means "impounding runoff water" in the local Chakhesang dialect. Zabo farming has been traditionally in practice as an indigenous farming model with its origin from Kikruma village under Phek district of Nagaland. This farming system consists of a water harvesting pond for the collection of rainwater and provision for soil erosion control, soil fertility management, and biodiversity conservation (Pulamte 2008).

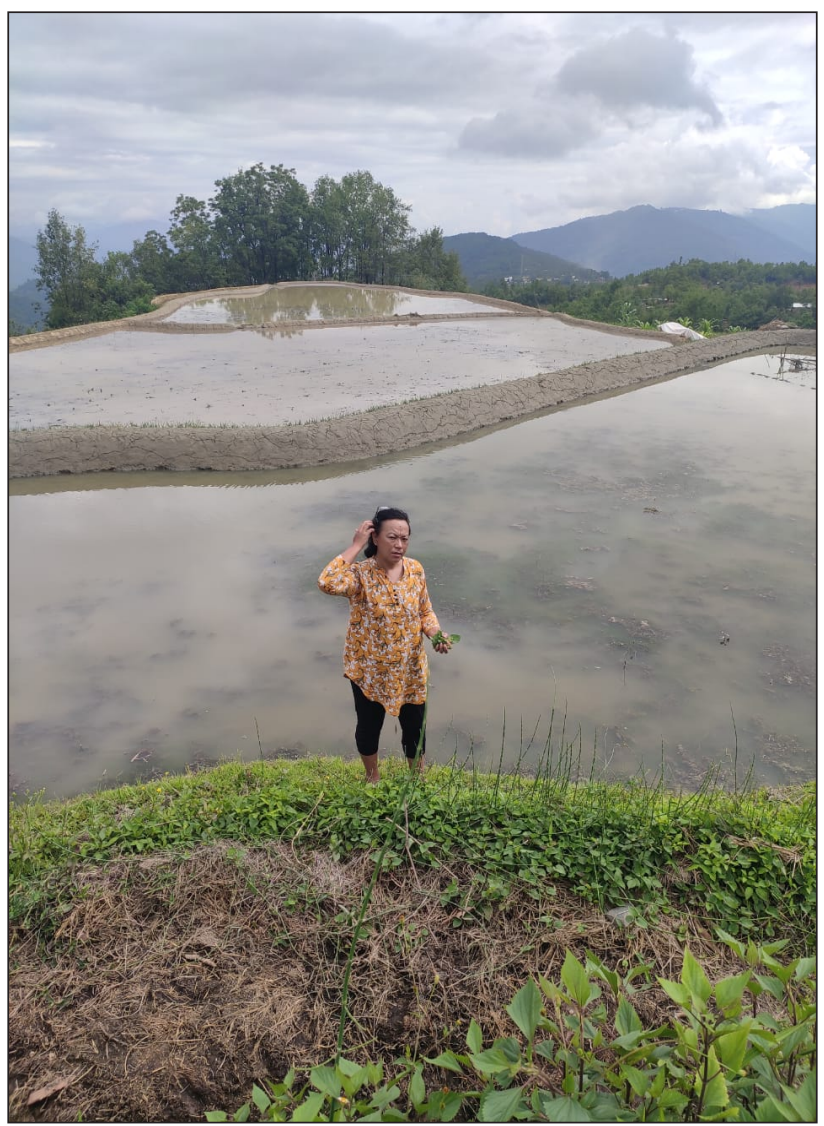

Fig. 1: Zabo farming
Zabo farming is basically an integrated farming model comprising of protected forest on the hilltop, animal husbandry, horticultural crops like vegetables with water harvesting pond at the midelevation, and paddy cultivation at lower elevation. Water harvesting structures or pond is dug out in the -mid-elevation of the hill below the protected forest area. The protected forest located on the hill top act as catchments area whereby runoff water after siltation is collected in the water harvesting pond. The water stored in the water harvesting ponds is mainly diverted to the irrigate paddy field located in the lower elevation, but it also serves the water need for the rearing of livestock and growing of vegetable and fruits which in around a pond. The irrigation water channel is allowed to pass through the animal yard, which carries with it the animal excreta, which are rich in manure and enriches the fertility of the soil.

In zabo farming, protected forest is reserved in the uppermost hilltop, in which forest vegetation is allowed to establish. This forest area at the top of the hill serves as a catchment area. Water collected from the catchment area serves as a source of irrigation water maintenance of livestock and for crop cultivation. The presence of vegetation intercepts more amount of rainfall during the rainy season. Below the forest area, a water harvesting pond for the storage of water is constructed. Silt retention tanks are constructed at several points where runoff water allow to retain in the silt retention tanks for few days before the runoff water is diverted into the water harvesting pond. Several water harvesting ponds may be dug out depending on the water requirement for the maintenance of crops and livestock. When multiple ponds are constructed, the ponds are laid out in such a way that the excess overflowing water from the upper pond flows into the ponds. The water storage ponds are compacted at the base to avoid seepage losses of water. Rearing of livestock and growing of vegetables and fruits are carried out nearby or just below the ponds area. Livestock components commonly maintained in the zabo farming includes cows, goats, pig, poultry, etc. The livestock is allowed to lose in open forest areas from the enclosure. The irrigation water in the water storage ponds is allowed to pass through the livestock enclosures so that the dung and urine of the animals are carried to the paddy fields with 
irrigation water. This enriches the soil fertility of the paddy field located at the lower elevation. Sometimes a water runoff is directly taken into the rice field when the terrains do not allow for the construction of a water storage pond. The field bunds are thoroughly rammed by beating with wooden sticks to avoid percolation and seepage of water. Rice husk and other boulders is also used on shoulder bunds of the terrace paddy fields so as to avoid excessive runoff (Dabral 2002).

Cultivation of paddy is the main component of zabo farming system, in this system, the paddy is cultivated, taking advantage of the continuous supply of water from the water harvesting ponds. Long duration (170-180 days) local varieties of rice are grown. The time of sowing for nursery is midMarch to mid-April, and transplanting is done in the month of June and generally harvested in the month of October and early November. The yield of paddy in zabo terraces varied from 1400 to 2500 $\mathrm{kg} / \mathrm{ha}$ with an average of $1950.00 \mathrm{~kg} / \mathrm{ha}$, which is comparatively higher than jhum or other methods of paddy cultivation prevalent in Nagaland. Paddy cum fish culture is practiced, where fish are reared along with the paddy during the growing season of paddy. In this process, fish fingerlings are released in the paddy field into a dug-out pit. When the paddy field is ready for harvest, the field is allowed to dry up by draining off the water in the field. As the field dried up, the fish moved into the pit, and from there, fishes are harvested. On average, 50 - 60 $\mathrm{kg}$ of fish is harvested per hectare from paddy cum fish culture (Singh et al. 2018).

\section{CONCLUSION}

Indigenous farming system developed by tribal farmers as an alternative of shifting cultivation has been found to be sustainable and ecological friendly apart from an increase in yield and productivity. Zabo farming It is a feasible farming practice in hilly topography like Nagaland and founded on the principle of integrated farming comprising of crops, livestock, fishery etc. This system has the inbuilt feature for conservation of ecological and biodiversity conservation and water resource management. The intervention of research and extension activities in such farming practices is required to make the system more efficient and adaptable in the long run.

\section{REFERENCES}

Sharma, U.C., Prasad, R.N. and Sonowal, D.K. 1994. An indigenous technique of soil and water conservation in north-eastern region- The Zabo system of farming, Soil and Water Conservation Challenges and Opportunities, Proceeding of $8^{\text {th }}$ ISCO conference. Ed. Bhushan, L. S. Abrol I. P. And Rama Mohan Rao M. S., Oxford and IBH, publication Co. Pvt. Ltd., New Delhi (India), 1994, 969-975.

Singh. R.K., Hannah. K., Asangla., Bharali, R. and Borkotoky, D. 2018. Zabo: A Time-tested Integrated Farming System Practiced by Chakhesang Tribe of Nagaland. Indian J. Hill Farm., 31(1): 188-192.

Pulamte. L. 2008. Indigenous agricultural systems of Northeast India; India, Science and Technology: 2008, published by National Institute of Science, Technology and Development Studies (NISTADS), CSIR, New Delhi.

Borthakur, D.N. 1982. Agriculture in the 1980's: strategy for development in the potential areas - North Eastern Hill Region, Paper Presented at the Silver Jubilee Conference of Agriculture Society of India, Calcutta.

Das, A., Ramkrushna, G.I., Choudhury, B.U., Munda, G.C., Patel, D.P., Ngachan, S.V., Ghosh, P.K., Tripathi, A.K., Das, S. and Kumar, M. 2012. Natural resource conservation through indigenous farming systems: wisdom alive in north-east India. Indian J. Tradit. Knowl., 11: 505-513.

Dabral, P.P. 2002. Indigenous Techniques of Soil and Water Conservation in North Eastern Region of India. $12^{\text {th }}$ ISCO Conference, Beijing, pp. 90-96.

Rathore, S.S., Karunakaran, K. and Prakash, B. 2010. Alder based farming system a traditional farming practices in Nagaland for amelioration of Jhum land. Indian J. Tradit. Knowl., 4: 677-680.

Kehie, M., Khamu, S. and Kehie P. 2017. Indigenous alder based farming practices in Nagaland, India: A sustainable agricultural model. J. Tradit. Folk Prac., 5(2): 82 - 152. 
